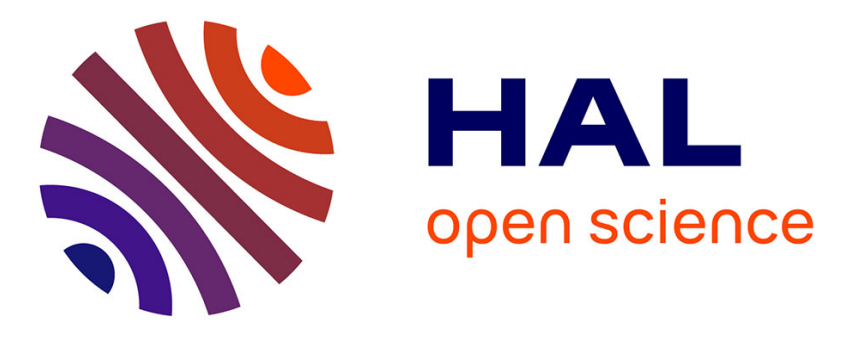

\title{
Revisiting the assembly of amino ester-based benzene-1,3,5-tricarboxamides: chiral rods in solution
}

Alaric Desmarchelier, Matthieu Raynal, Patrick Brocorens, Nicolas

Vanthuyne, Laurent Bouteiller

\section{To cite this version:}

Alaric Desmarchelier, Matthieu Raynal, Patrick Brocorens, Nicolas Vanthuyne, Laurent Bouteiller. Revisiting the assembly of amino ester-based benzene-1,3,5-tricarboxamides: chiral rods in solution. Chemical Communications, 2015, 51, pp.7397-7400 10.1039/C5CC01513H . hal-01141988

\section{HAL Id: hal-01141988 \\ https://hal.sorbonne-universite.fr/hal-01141988}

Submitted on 14 Apr 2015

HAL is a multi-disciplinary open access archive for the deposit and dissemination of scientific research documents, whether they are published or not. The documents may come from teaching and research institutions in France or abroad, or from public or private research centers.
L'archive ouverte pluridisciplinaire HAL, est destinée au dépôt et à la diffusion de documents scientifiques de niveau recherche, publiés ou non, émanant des établissements d'enseignement et de recherche français ou étrangers, des laboratoires publics ou privés. 


\title{
Revisiting the assembly of amino ester-based benzene-1,3,5- tricarboxamides: chiral rods in solution
}

\author{
Alaric Desmarchelier, ${ }^{a b}$ Matthieu Raynal, ${ }^{* a b}$ Patrick Brocorens, ${ }^{\mathrm{c}}$ Nicolas Vanthuyne ${ }^{\mathrm{d}}$ and Laurent \\ Bouteiller*ab
}

\begin{abstract}
Some benzene-1,3,5-tricarboxamide (BTA) monomers derived from $(L) \alpha$-amino esters self-assemble into long rods at millimolar concentrations, and display a strong chiral amplification effect. These rods are in competition with dimeric species.
\end{abstract}

Synthetic helical macromolecules with a tunable chirality and rigidity in solution ${ }^{1}$ have found applications as switchable chiral liquid crystalline materials ${ }^{2}$ and asymmetric catalysts. ${ }^{3}$ In this context, helical supramolecular polymers are particularly interesting, because the reversible nature of their backbone imparts an easy access to copolymers and to chirality amplification studies, as well as an improved stimuliresponsiveness. ${ }^{4}$

Chiral supramolecular helices formed by the self-assembly of benzene-1,3,5-tricarboxamide (BTA) monomers constitute a platform of choice for that objective. ${ }^{4 \mathrm{~d}}$ The self-assembly behaviour of BTAs bearing alkyl amide functions (alkyl BTAs) in alkanes is well understood: threefold hydrogen bonds between the amide functions and an aromatic interaction between the central rings of adjacent BTA monomers are the driving forces for the formation of long stacks (Chart 1, right). Moreover, the position of the stereogenic centre along the alkyl group with respect to the amide function has been shown to control the handedness of the helix ${ }^{5}$ and mixtures of alkyl BTAs show strong "majority rules" and "sergeants-and-soldiers" effects. ${ }^{6}$ Such a chiral amplification phenomenon expressed at the molecular level has been exploited for controlling racemization/deracemization processes $^{7}$ and for designing asymmetric catalysts. ${ }^{8}$ Building BTA molecules from $\alpha$-amino esters (ester BTAs) is a quite simple and potentially powerful strategy that can be used to incorporate a wide range of chiral pendants at the $\alpha$-position of the amide functions. . BTAs derived from $(L)$-valine methyl ester, ${ }^{9 \mathrm{c}}(L)$-methionine methyl ester, ${ }^{9 \mathrm{k}}$ and $(L)$-glutamic acid dimethyl ester ${ }^{9 a}$ indeed self-assemble into chiral helical stacks in their crystalline states, similarly to alkyl BTAs. In contrast, little is known about the association behaviour of ester BTAs in solution, and the only two studies available hint at a poor selfassociation. van Esch et al. found that BTA derived from $\alpha$ amino octyl esters are poor gelators of organic solvents and attributed this effect to the steric bulkiness of the amino ester side-chain (Phe and Leu) and to interference of the ester moiety itself (Gly). ${ }^{9 \mathrm{e}}$ Meijer et al. showed that changing one alkyl chain of trioctyl BTA by one ester chain (amide function derived from
( $L$ )-phenylalanine octyl ester) prevents the cooperative formation of long stacks in methylcyclohexane. ${ }^{9 g}$ They also studied the association behaviour of a BTA bearing three amide functions derived from $(L)$-phenylalanine octyl ester (closely related to BTA Phe, vide infra). No cooperative aggregation process was detected at the concentrations investigated $(5-50 \mu \mathrm{M})$ and only "ill-defined aggregates" were formed. These disappointing results could suggest that ester BTAs are not suitable building blocks to prepare long chiral rods. In fact, we now report that long chiral rods can indeed be obtained by self-assembly of ester BTAs in solution by an appropriate choice of amino ester and concentration, and that these ester BTAs can efficiently impose their helical bias to rods of achiral BTAs.

BTAs derived from $(L)$-methionine, $(L)$-norleucine and $(L)$-phenylalanine dodecyl ester (BTA Met, BTA Nle and BTA Phe, respectively, Chart 1) have been prepared in their pure form (ee $>99 \%))^{\dagger}$ The self-assembly behaviour of these ester BTAs are compared with that of a trialkyl BTA, BTA C8*, known to form long chiral rods in bulk and in solution. ${ }^{5}$

A first hint for the different self-assembly behaviour in solution of these ester BTAs was obtained by comparing their viscosity in cyclohexane. At $0.4 \mathrm{wt} \%(\sim 4 \mathrm{mM})$ BTA Met and BTA Phe have relative viscosities of 7.3 and 1.4, respectively while solutions of BTA Nle are not viscous (Fig. S1). These differences in relative viscosity reveal the formation of large supramolecular objects for BTA Met and BTA Phe in cyclohexane.

This observation was corroborated by small-angle neutron scattering (SANS) analyses in deuterated cyclohexane at $1 \mathrm{wt} \%$ (ca. $10 \mathrm{mM}$ ) (Fig. S2). At $23^{\circ} \mathrm{C}$, the scattering profiles of BTA Met and BTA Phe are characteristic of long fibrillar scatterers. The $q^{-1}$ dependence observed at low angles is representative of rigid cylindrical objects that are longer than $200 \AA$. Fitting of the data using the form factor for rigid rods with a circular cross section $^{10}$ gave cross-section radii of 16.0 and $16.5 \AA$ for BTA Met and BTA Phe, respectively. These values are close to that calculated for a monomer in a fully extended conformation (19.5 $\AA$ ) and are thus consistent with a monomolecular cross-section of the objects. In sharp contrast, the scattering curve of BTA Nle exhibits no $q^{-1}$ dependence. For that system, the scattering intensity, which is proportional to the mass of the object, is low. The data can be fitted using the form factor for a sphere ${ }^{11}$ yielding a radius of $13.5 \AA$ and a mass of $2000 \mathrm{~g} \cdot \mathrm{mol}^{-1}$. These 


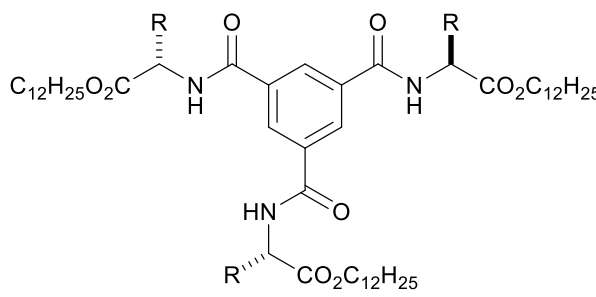

BTA Met $\left(\mathrm{R}=(\mathrm{S})-\mathrm{CH}_{2} \mathrm{CH}_{2} \mathrm{SCH}_{3}\right)$ BTA Nle $\left(\mathrm{R}=(\mathrm{S})-\mathrm{CH}_{2} \mathrm{CH}_{2} \mathrm{CH}_{2} \mathrm{CH}_{3}\right)$ BTA Phe $\left.\left(\mathrm{R}=(\mathrm{S})-\mathrm{CH}_{2} \mathrm{C}_{6} \mathrm{H}_{5}\right)\right)$<smiles>[R]NC(=O)c1cc(C(=O)NCC)cc(C(=O)NCC)c1</smiles>

BTA $\mathrm{C}_{8}{ }^{*}\left(\mathrm{R}=(\mathrm{S})-\mathrm{CH}\left(\mathrm{CH}_{3}\right)\left(\mathrm{CH}_{2}\right)_{5} \mathrm{CH}_{3}\right)$ BTA C8 $\left(\mathrm{R}=\mathrm{CH}_{2}\left(\mathrm{CH}_{2}\right)_{6} \mathrm{CH}_{3}\right)$

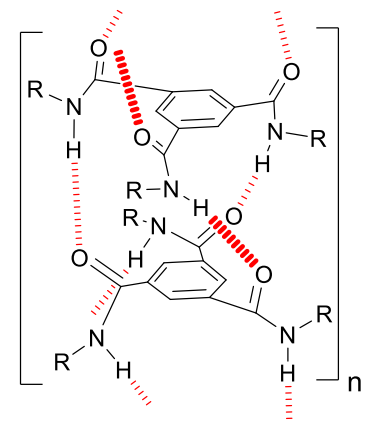

Chart 1 Ester BTAs studied in this work (left), reference alkyl BTA (middle) and structure of the stacks formed by alkyl BTAs in alkanes.

values suggest that BTA Nle exists as a dimeric species $\left(\mathrm{M}_{\text {spherical }}\right.$ object $/ \mathrm{M}_{\text {monomer }}=1.9$ ) in cyclohexane at $1 \mathrm{wt} \%$. The stability of the rigid objects formed by BTA Met and BTA Phe was probed by heating to $70^{\circ} \mathrm{C}$. For BTA Met, the scattering profile indicates that long cylindrical objects are still present but in a lower amount than at $23^{\circ} \mathrm{C}$ (Fig. S2). For BTA Phe, the scattering curve at $70^{\circ} \mathrm{C}$ is similar to that obtained for BTA Nle at $23^{\circ} \mathrm{C}$, suggesting a transition from long objects to dimeric species.

High-sensitivity differential scanning calorimetry (DSC) is well adapted to characterize such a transition. ${ }^{12}$ DSC analyses (Fig. S3) of $1 \mathrm{mM}$ cyclohexane solutions show relatively sharp endothermal peaks with maxima at $\mathrm{T}^{*}=37^{\circ} \mathrm{C}$ and $\mathrm{T}^{*}=29^{\circ} \mathrm{C}$ for BTA Met and BTA Phe, respectively. These features are consistent with the dissociation of the long objects upon increasing the temperature, as observed in the SANS analyses. Moreover, the stability of the assemblies to dilution was probed by isothermal titration calorimetry (ITC). The dilution of a $5 \mathrm{mM}$ BTA solution into pure cyclohexane first yields a large endothermal signal characteristic for the dissociation of hydrogen-bonded assemblies (Fig. S4). As concentration increases in the cell, a sharp decrease of the heat evolved indicates that the assemblies become stable. Therefore, the concentration below which the rods disassemble ( $\left.\mathrm{c}^{*}\right)$ is $0.28 \mathrm{mM}$ and $0.44 \mathrm{mM}$ for BTA Met and BTA Phe, respectively (Fig. S4) ${ }^{\dagger \dagger}$ The sharpness of the heat decrease (in ITC) and of the endothermal peak (in DSC) are consistent with a cooperative transition between the long assemblies and the dimeric species. ${ }^{13}$ In contrast, no significant heat effect has been observed for BTA Nle, in agreement with the absence of rods, and suggesting a very high stability of the dimeric aggregates (Figs. S3 and S4).

In order to gain more information on the local structure of these objects, we performed a series of spectroscopic IR, UV and circular dichroism (CD) measurements. First of all, the structure of the long assemblies formed by BTA Met and BTA Phe in cyclohexane above their $\mathrm{c}^{*}$ (and below their $\mathrm{T}^{*}$ ) was probed. IR analyses confirm the formation of amide-bonded supramolecular polymers as the main species since the frequencies of the amide vibrations are characteristic of fully associated $\mathrm{NH}$ and amide $\mathrm{CO}$ moieties (Figs. S5 and S6). The UV absorption spectra (Fig. S7) show an absorption band at $\sim 195 \mathrm{~nm}$ in cyclohexane, which is hypsochromically shifted $(\Delta \lambda=14 \mathrm{~nm})$ compared to ethanol (in which BTAs are molecularly dissolved). This blue shift is similarly observed for BTA $\mathbf{C 8}^{*}$ and can be assigned to rod-like

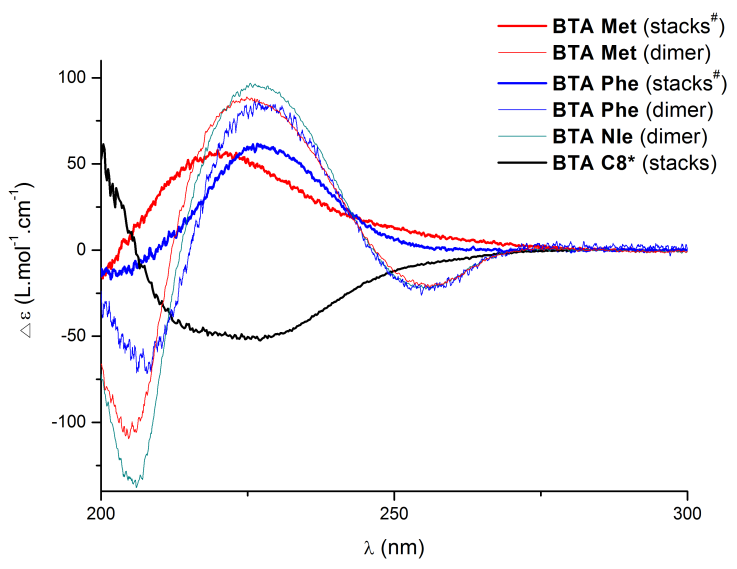

Fig. 1 CD spectra of ester BTAs and BTA C8* in cyclohexane. The spectra were recorded at $0.125 \mathrm{mM}$ (dimer, thin lines) and $2.0 \mathrm{mM}$ (stacks, thick lines). The monomers are not CD active (Fig. S8). \# At these concentrations BTA Met and BTA Phe predominantly exist as stacks but dimers are also present. ${ }^{\dagger \dagger}$

objects that contain extended $\pi$-stacks of excitonically-coupled chromophores. ${ }^{6 a}$ Finally, the shape and intensity of their CD spectra are similar to those of BTA C8* (molar ellipticity $\Delta \varepsilon \sim 55$ L.mol ${ }^{-1} . \mathrm{cm}^{-1}, \lambda_{\max } \sim 225 \mathrm{~nm}$, Fig. 1). All together, these results confirm that BTA Met and BTA Phe do form amide-bonded helical stacks with a preferred handedness in cyclohexane. The positive Cotton effect observed in their CD spectra is indicative of a right-handed helix ${ }^{14}$ consistent with the handedness of the helices formed by the BTA derived from $(L)$-methionine methyl ester in the crystalline state. ${ }^{9 \mathrm{k}}$ Interestingly, ester BTAs and BTA C8* exhibit opposite Cotton effects even though they all possess a $S$-configured centre at the $\alpha$-position of the amide functions.

In a similar way, the molecular structure of the dimeric species was investigated. IR analyses of BTA Nle (Figs. S5 and S6) clearly demonstrate that the $\mathrm{NH}$ protons are bonded to the ester (rather than to the amide) functions in the dimer: i) the NH (3388 $\left.\mathrm{cm}^{-1}\right)$ and ester CO $\left(1728 \mathrm{~cm}^{-1}\right)$ frequencies are consistent with a $\mathrm{NH}$ proton being associated with an ester carbonyl, ${ }^{15}$ and ii) amide CO groups are free (frequencies at $1675 \mathrm{~cm}^{-1}$ and 1530 $\mathrm{cm}^{-1}$ for the amide I and amide II region, respectively). The IR spectrum of BTA Nle does not vary over the range of concentrations (Fig. S9a) and temperatures (Fig. S10) investigated, providing another indication that that BTA does not 


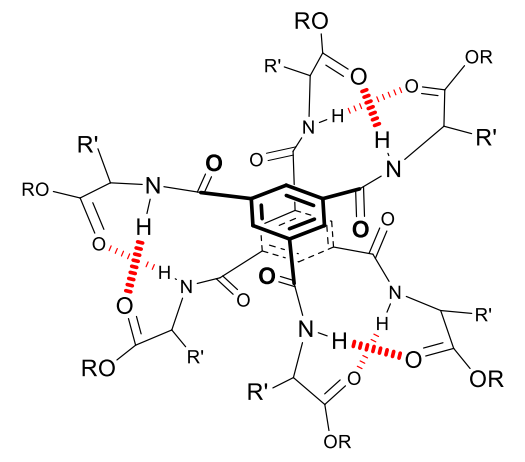

ester-bonded dimer

for BTA Met, BTA Phe and BTA Nle

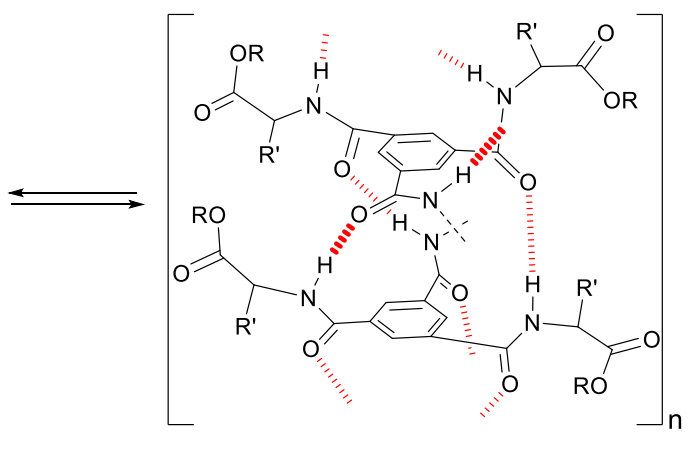

long helical stacks

for BTA Met and BTA Phe

Fig. 2 Proposed molecular structures for the dimer and the long helical assemblies formed by ester BTAs in cyclohexane.
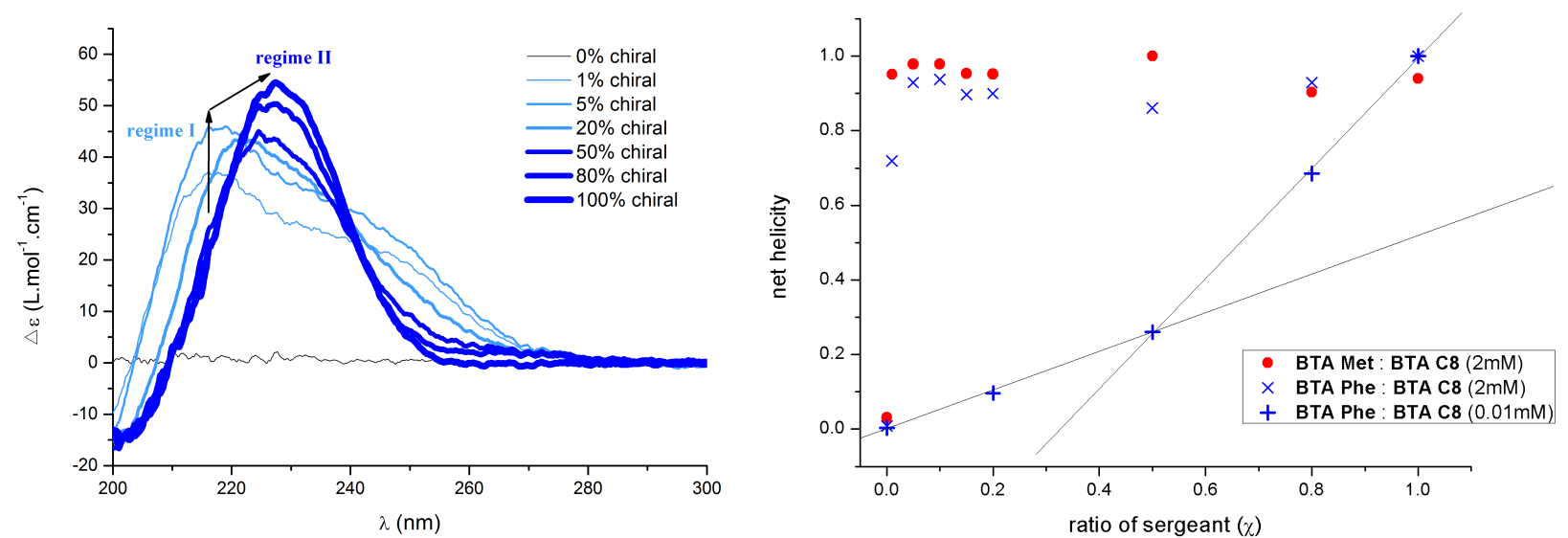

Fig. 3 Left: CD spectra of mixtures of BTA Phe:BTA C8. Total concentration $=2.0 \mathrm{mM}$, cyclohexane, $20^{\circ} \mathrm{C}$. Right: net helicity versus fraction of "sergeant" for mixtures of BTA Met:BTA C8 and BTA Phe:BTA C8. Net helicity $=\Delta \varepsilon \operatorname{measured} / \Delta \varepsilon \max (\Delta \varepsilon$ was determined at the isodichroic point for BTA Met and BTA Phe, at $2.0 \mathrm{mM}(\lambda=234 \mathrm{~nm}$ and $238 \mathrm{~nm}$, respectively $)$ or at $225 \mathrm{~nm}$ for BTA Phe, at $0.01 \mathrm{mM})$.

form stacks. The UV absorption spectra of dimers are quite similar and resemble the spectra of their monomers (Fig. S7), as expected for species lacking extended aromatic interactions. Rather unexpectedly, dimers are strongly CD active (Fig. 1). The shape and intensity of their CD spectra significantly differ from those of the stacks: they exhibit three maxima $\left(\lambda^{-}=205 \mathrm{~nm}\right.$, $\left.\lambda^{+}=225 \mathrm{~nm}, \lambda^{-}=255 \mathrm{~nm}\right)$ and their molar ellipticity is higher $(\Delta \varepsilon \sim$ $85 \mathrm{~L} . \mathrm{mol}^{-1} \cdot \mathrm{cm}^{-1}$ at $\left.225 \mathrm{~nm}\right)$. We hypothesize that such a strong CD signal originates from a very rigid organization of the chromophores at the proximity of the chiral centres. The dimer is very stable and cannot be totally disrupted even by heating a $0.0125 \mathrm{mM}$ cyclohexane solution to $70^{\circ} \mathrm{C}$ (Fig. S11)! The dimer can however be disrupted by adding a polar solvent (Fig. S14). To account for all these data, we propose, on the basis of molecular modelling simulations, ${ }^{\$}$ a molecular arrangement for the dimeric form of the ester BTAs (Fig. 2) in which the six-fold hydrogen bonds between the BTA monomers may explain the high stability of the dimer.

The association behaviour of the investigated ester BTAs is summarized in Fig. 2. BTA Met and BTA Phe self-assemble into two competing forms: an ester-bonded dimer and an amidebonded helical polymer, both of which are CD active. BTA Nle only assembles into ester-bonded dimers, in these conditions. Our results explain why previous studies overlooked the formation of rods from ester BTAs: i) the assembly of ester BTAs is strongly dependent on the nature of the amino-ester side-group, and ii) at low concentrations $(50 \mu \mathrm{M})$, BTA Phe exists as very stable CD-active dimeric species; stacks only form at concentrations ten times higher. ${ }^{9 \mathrm{~g}}$

Despite their nearly isosteric structures, BTA Met forms helical stacks while BTA Nle does not. This difference points out the importance of weak non-covalent interactions (in addition to the hydrogen bond and aromatic interactions) to stabilize the rod-like architecture. Short-range contacts (e.g. $3.5 \AA$ between the sulfur of the methionine ester and an ester carbonyl) are present in the X-ray structure of a BTA derived from $(L)$-methionine methyl ester, ${ }^{9 \mathrm{k}}$ and we hypothesize that such contacts drive the formation of the long stacks over the dimers for BTA Met. Similarly, we propose that $\pi-\pi$ interactions between the phenylalanine aromatic rings govern the formation of stacks for BTA Phe. A similar hypothesis was made by van Esch et al. to explain the better gelation of BTA Phe (with octyl instead of dodecyl ester side chains) compared to BTAs derived from glycine and valine. ${ }^{9 e}$

Finally, "sergeants-and-soldiers" experiments were performed by mixing $2.0 \mathrm{mM}$ cyclohexane solutions of the $\mathrm{CD}$-active ester BTAs (BTA Met or BTA Phe) with the CD-silent alkyl BTA C8. CD spectra were recorded for different fractions $(\chi)$ of ester BTAs (Fig. 3 left for BTA Phe and Fig. S12 for BTA Met) and 
$\Delta \varepsilon$ was monitored at $\sim 235 \mathrm{~nm}$ (Fig. 3 right). A very steep increase in the magnitude of the $\mathrm{CD}$ effect was observed upon addition of only $1 \mathrm{~mol} \%$ of ester BTA. Both BTA Met and BTA Phe are thus able to induce a preferential helicity in aggregates mainly consisting of BTA C8, showing that the chirality present in ester BTAs can be efficiently transferred. This result is remarkable because, as previously reported, ${ }^{9 \mathrm{~g}}$ and as shown on Figs. 3 and S13, no amplification occurs at lower concentrations $(10 \mu \mathrm{M})$. The formation of ester BTA : BTA C8 helical copolymers is evidenced by the presence of two regimes: i) the shape of the CD spectra at low $\chi$ values is similar to that of BTA C8* (with a maximum at $\sim 220 \mathrm{~nm}$ and a strong shoulder at $240 \mathrm{~nm}$, regime I) indicating the incorporation of ester BTA within stacks of BTA C8, ii) at high $\chi$ values the CD spectra have the same shape as those displayed by pure stacks of ester BTAs (regime II). Interestingly, the handedness of the ester BTA : BTA C8 co-polymers is imposed by the ester BTA, even for very low proportions $(\chi=0.01)$

In conclusion, ester BTAs are very accessible building blocks that can self-assemble into long rods or simple dimers at $\mathrm{mM}$ concentrations. The chosen amino acid residue introduced in ester BTAs not only dictates whether long rods or dimers are formed, but it also allows strong chirality amplification effects.

Support from the French Agence Nationale de la Recherche is acknowledged (project ANR-13-BS07-0021 SupraCatal). We thank François Boué (LLB, Saclay) for assistance with SANS experiments.

\section{Notes and references}

${ }^{a}$ Sorbonne Université, UPMC Univ Paris 06, UMR 8232, IPCM, Chimie des Polymères, F-75005 Paris, France.laurent.bouteiller@upmc.fr ${ }^{b}$ CNRS, UMR 8232, IPCM, Chimie des Polymères, F-75005 Paris, France

${ }^{c}$ Service de Chimie des Matériaux Nouveaux, Université de Mons/Materia Nova, Place du Parc, 20, B-7000 Mons, Belgium ${ }^{d}$ Aix Marseille Université, CNRS, iSm2, UMR 7313, 13397 Marseille cedex 20, France

$\dagger$ Electronic Supplementary Information (ESI) available: general procedures, synthesis and characterization of ester BTAs and Figs. S1 to S14. See DOI: 10.1039/b000000x/

$\dagger \dagger$ Despite the cooperative transition observed between dimers and stacks, dimers are still present at $\mathrm{mM}$ concentrations in cyclohexane. $10 \mathrm{mM}$ cyclohexane solutions of BTA Met and BTA Phe contain 5\% and 7\% of dimers, respectively, while $2 \mathrm{mM}$ solutions contain $22 \%$ and $28 \%$ of dimers, respectively (see Figs. S5, S9 and S10).

$\$$ The relative stability of different hydrogen bond patterns in the dimer has been evaluated by molecular dynamics simulations using the Dreiding force field in the Materials Studio modelling package.

1. (a) M. M. Green, J. W. Park, T. Sato, A. Teramoto, S. Lifson, R. L. B. Selinger and J. V. Selinger, Angew. Chem. Int. Ed., 1999, 38, 3139; (b) K. Maeda and E. Yashima, Top. Curr. Chem., 2006, 265, 47; (c) E. Yashima, K. Maeda, H. Iida, Y. Furusho and K. Nagai, Chem. Rev., 2009, 109, 6102.

2. D. Pijper, M. G. M. Jongejan, A. Meetsmia and B. L. Feringa, J. Am. Chem. Soc., 2008, 130, 4541.

3. (a) R. P. Megens and G. Roelfes, Chem. Eur. J., 2011, 17, 8514; (b) Y. Akai, T. Yamamoto, Y. Nagata, T. Ohmura and M. Suginome, $J$. Am. Chem. Soc., 2012, 134, 11092; (c) Y. Nagata, T. Nishikawa and M. Suginome, J. Am. Chem. Soc., 2014, 136, 15901; (d) T. Yamamoto, Y. Akai and M. Suginome, Angew. Chem. Int. Ed., 2014, 53, 12785 .

4. (a) D. B. Amabilino and J. Veciana, Top. Curr. Chem., 2006, 265, 253; (b) A. R. A. Palmans and E. W. Meijer, Angew. Chem. Int. Ed., 2007, 46, 8948; (c) A. Lohr and F. Wurthner, Isr. J. Chem., 2011, 51,
1052; (d) S. Cantekin, T. F. A. de Greef and A. R. A. Palmans, Chem. Soc. Rev., 2012, 41, 6125

5. P. J. M. Stals, M. M. J. Smulders, R. Martín-Rapún, A. R. A Palmans and E. W. Meijer, Chem. Eur. J., 2009, 15, 2071.

6. (a) M. M. J. Smulders, A. P. H. J. Schenning and E. W. Meijer, J Am. Chem. Soc., 2008, 130, 606; (b) M. M. J. Smulders, I. A. W. Filot, J. M. A. Leenders, P. van der Schoot, A. R. A. Palmans, A. P. H. J. Schenning and E. W. Meijer, J. Am. Chem. Soc., 2010, 132, 611; (c) M. M. J. Smulders, P. J. M. Stals, T. Mes, T. F. E. Paffen, A. P. H. J. Schenning, A. R. A. Palmans and E. W. Meijer, J. Am. Chem. Soc., 2010, 132, 620.

7. S. Cantekin, H. M. M. ten Eikelder, A. J. Markvoort, M. A. J. Veld, P. A. Korevaar, M. M. Green, A. R. A. Palmans and E. W. Meijer, Angew. Chem. Int. Ed., 2012, 51, 6426.

8. (a) M. Raynal, F. Portier, P. W. N. M. van Leeuwen and L. Bouteiller, J. Am. Chem. Soc., 2013, 135, 17687; (b) E. Huerta, B. van Genabeek, B. A. G. Lamers, M. M. E. Koenigs, E. W. Meijer and A. R. A. Palmans, Chem. Eur. J., DOI: 10.1002/chem.201405410.

9. (a) D. Ranganathan, S. Kurur, R. Gilardi and I. L. Karle, Biopolymers, 2000, 54, 289; (b) I. L. Karle and D. Ranganathan, J. Peptide. Res., 2005, 65, 65; (c) P. P. Bose, M. G. B. Drew, A. K. Das and A. Banerjee, Chem. Commun., 2006, 3196; (d) K. P. van den Hout, R. Martín-Rapún, J. A. J. M. Vekemans and E. W. Meijer, Chem. Eur. J., 2007, 13, 8111; (e) M. de Loos, J. H. van Esch, R. M. Kellogg and B. L. Feringa, Tetrahedron, 2007, 63, 7285; (f) G. Srinivasulu, B. Sridhar, K. R. Kumar, B. Sreedhar, V. Ramesh, R. Srinivas and A. C. Kunwar, J. Mol. Struct., 2011, 1006, 180; (g) M. A. J. Veld, D. Haveman, A. R. A. Palmans and E. W. Meijer, Soft Matter, 2011, 7, 524; (h) H. Cao, P. F. Duan, X. F. Zhu, J. Jiang and M. H. Liu, Chem. Eur. J., 2012, 18, 5546; (i) Y. T. Dai, X. Zhao, X. Y. Su, G. Y. Li and A. Zhang, Macromol. Rapid. Commun., 2014, 35, 1326; (j) Y. Ishioka, N. Minakuchi, M. Mizuhata and T. Maruyama, Soft Matter, 2014, 10, 965; (k) P. Jana, A. Paikar, S. Bera, S. K. Maity and D. Haldar, Org. Lett., 2014, 16, 38.

10. F. Lortie, S. Boileau, L. Bouteiller, C. Chassenieux, B. Deme, G. Ducouret, M. Jalabert, F. Laupretre and P. Terech, Langmuir, 2002, 18, 7218.

11. M. Bergstrom and J. S. Pedersen, Phys. Chem. Chem. Phys., 1999, 1, 4437.

12. M. Bellot and L. Bouteiller, Langmuir, 2008, 24, 14176.

13. A. Arnaud and L. Bouteiller, Langmuir, 2004, 20, 6858.

14. Y. Nakano, T. Hirose, P. J. M. Stals, E. W. Meijer and A. R. A. Palmans, Chem. Sci., 2012, 3, 148.

15. M. T. Scerba, A. F. DeBlase, S. Bloom, T. Dudding, M. A. Johnson and T. Lectka, J. Phys. Chem. A, 2012, 116, 3556. 